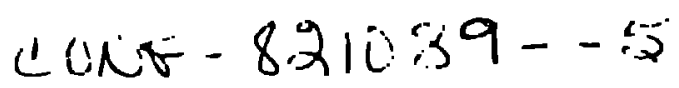

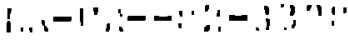

$$
\begin{aligned}
& \text {.11. }
\end{aligned}
$$

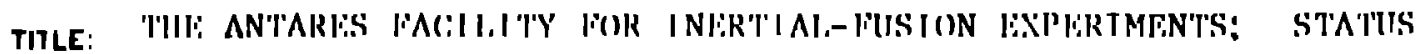
ANI PI.ANS

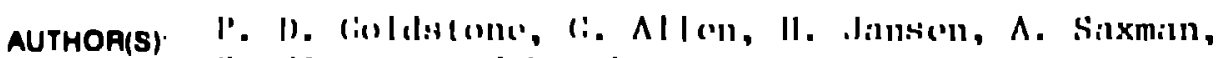
S.

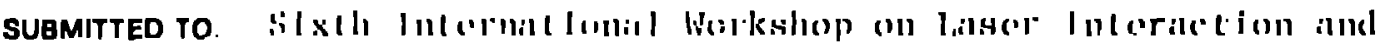

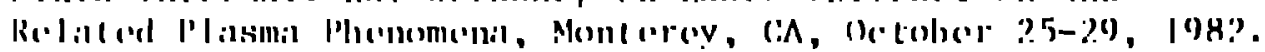


THE ANTARES FACILITY FOR INERTIAL-FUSION EXPERIMENTS

\section{- STATUS AND PLANS}

P. П. Goldstone, G. Allen, H. Jansen,

A. Saxman, S. Singer, and M. Thuot

Los Alamos National Laboratory

Los Alamos, NM 87545

\section{NTRODUCTION}

In the last decade several increasingly powerfal short pulse $\mathrm{CO}_{2}$ lasers have been constructed at Los Alamos National Laboratory to investiqate the feasibility of $\mathrm{CO}$, as an inertial fusion driver. The advantage of $\mathrm{CO}_{2}$, a gas laser with hich rep-rate capability, electrical efficiency as high as $10 \%$, and scalab:lity to large energies, must uutweigh important difficulties in tarnet physics due to the copious production of suprathermal electrons if $\mathrm{CO}_{2}$ is to be considered a viable driver option.

Since 1978, Los Alamos has used the 10-kJ, eioht beam Helios laser 1 to perform a variety of experiments aimed at elucidating basic laser-matter interaction mechanisms and beginning to determine the scalability of $\mathrm{CO}_{2}$-ririven targets to lighh driver energies. Antares, currently under construztion, will be the next $\mathrm{CO}_{2}$ laser used to further the experimental ICF pronram. Scheduled for operation carly in FY-84, the Antares laser is dessinned to provide $3(0-40 \mathrm{~kJ}$ in a nominal 0.7 ns bulse, atilizing 2.4 independently pointable beams. Since llelios is generally limited to $-5 k_{s}$ operation in most tarqet experiments, this will provide a siqnificant increase in the encrov aviliable for torret experiments, enabling us to study the morey scilling of larget. interaction phenomena as well as to perform experimenl.s which are eneruy-limited at. Helios. 


\section{THE ANTARES LASER SYSTEM}

Antares is a master oscillator-power amplifiei system, consisting of a short pulse oscillator similar to that used in the Helios laser, 1 preamplifiers, intermediate driver ampli.fiers, and a pair of large electron-beam-controlled discharge power amplifiers. A multiline oscillator for pulse lengthening and shaping is being developed.

Fach power amplifier is double-passed for efficient energy extraction and produces an annular array of 12 trapezoidal beams (sectors) for a total of 24 beams, which are independently pointed and focused on target in a six-sided - illumination pattern. A schematic of the facility beam path is shown in Fig. 1. The optical systam is designed to fucus 80" of the energy of each sector into a $300 \mathrm{\mu m}$ diameter spot with a pointing error of $\pm 25 \mu \mathrm{m}$ at the target (each sector is an effective $f / 6$ bealn). The final tuinina and focusing mirrors are mounted on a larne space frame within the $\theta_{-1 n}$ diameter tarjet chamber. In order to eliminate parasitic oscillations? which extract crerqy beforo short pulse amplification can take place, the Antares amplifiers are pumped to a qain of $\mathrm{nL}=7$ in 1.5 "s and the power amplifiers are separated from the target by no meters to reduce the number of available round trips for pardsitics during the pump time. (There is also the provision for a saturable absorber gas cell in the power amplifier.) The sections below will discuss the details and status of major components of the? Antares laser system.

\section{FRONT END SUIBSYSTF.M}

?he Antares irorite encl, shown schematicalily in Fill.?, originates with a single longitudinal mode gain-swilcherl oscillator with three pockols rells in sories lo provide? an enercy contrast ratio of approxinately lolo at the out.put of the front end; this contrast ratio is sufficient: to provide? nenligible prepulse on turout for the highest anticipated iystem

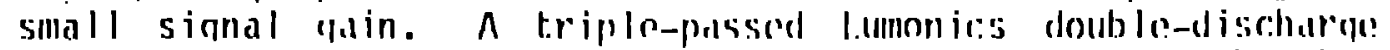
Tlin laser anplifies the nominal I ns pulse: the beam is them

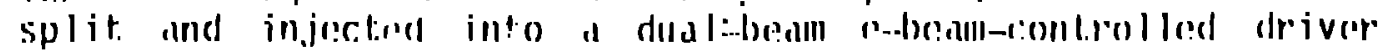

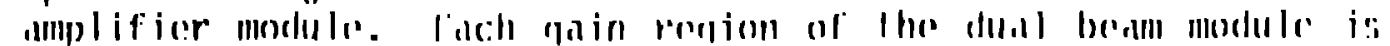

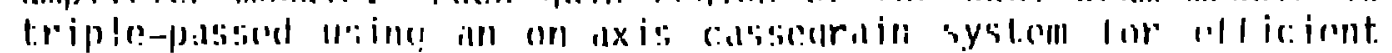

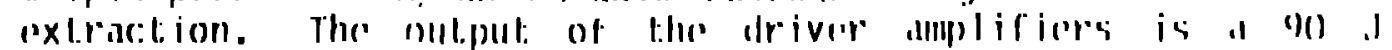

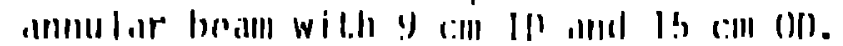

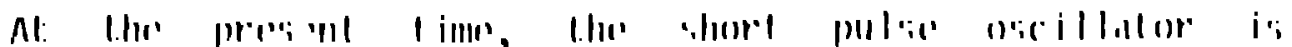

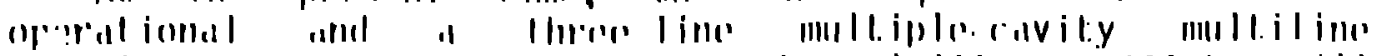

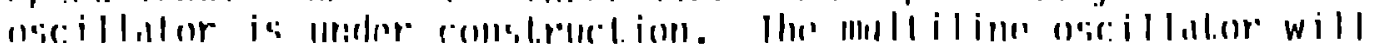

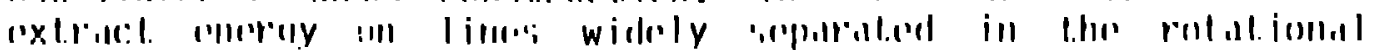

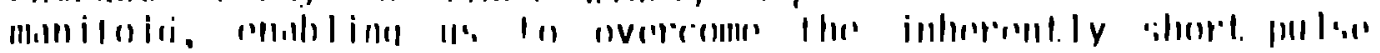




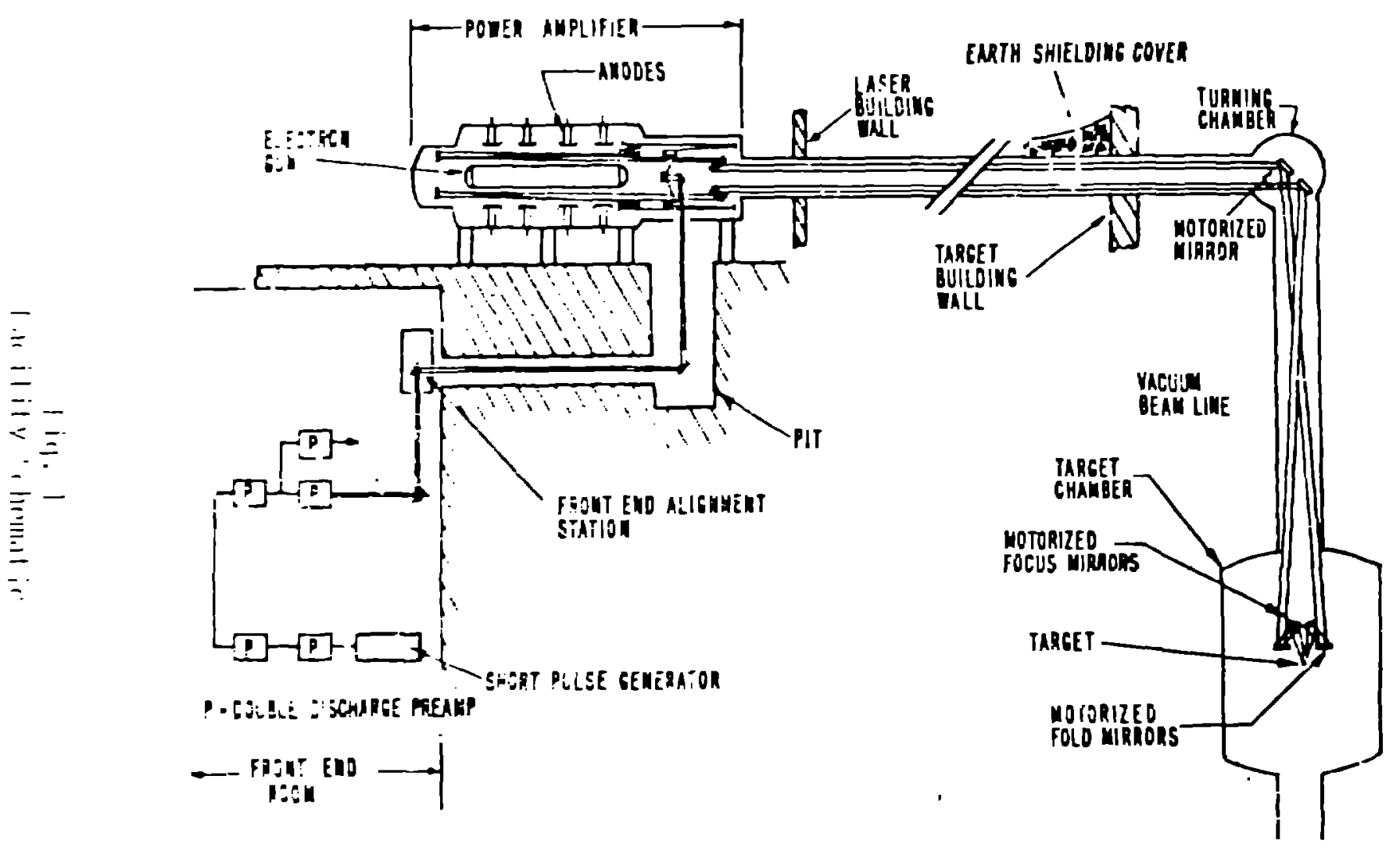


nature of heavily saturated amplifiers to tailor the pulse shapeon turget. Both driver amplifier discharges are electrically operational and, on one beamline, more than 500 shots have been fired extracting - $100 \mathrm{~J}$. This exceeds specifications and is sufficient to drive the power amplifier

$r$ energy extraction tests. The repitition rate of the front

1 system is appioximately 3 min/shot, limited by chargina I 'es for the driver ampliiier; total alionment time from a rlead $s_{i}$-t is 2. hours. Overall reliability of the front end is cur eritly 95\% and is improving toward the specified $99 \%$.

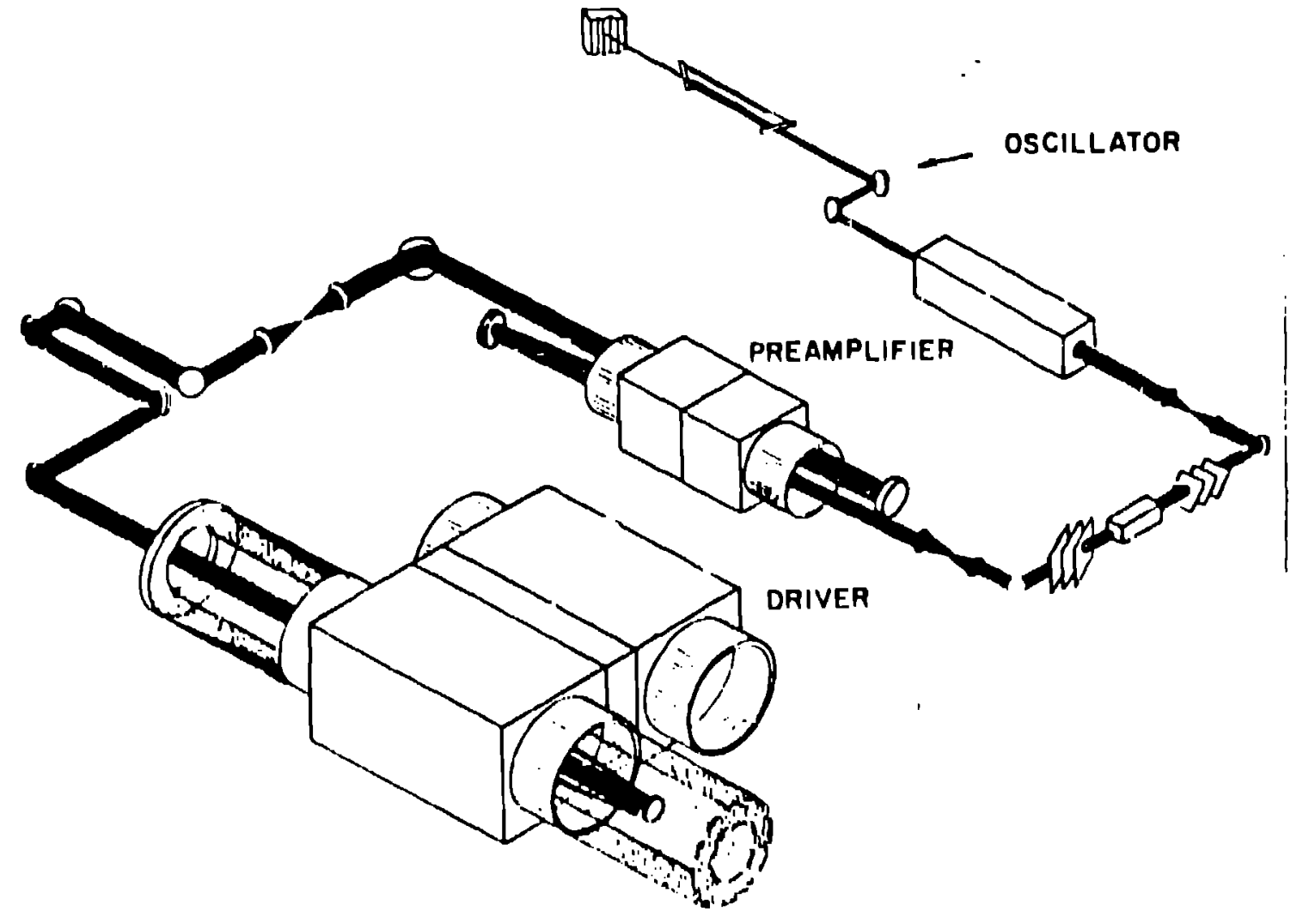

I:il. :

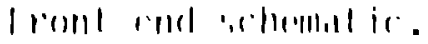

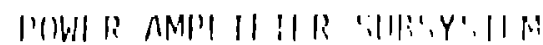

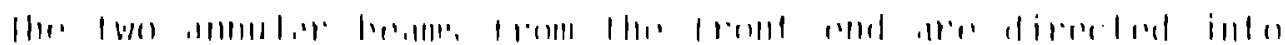

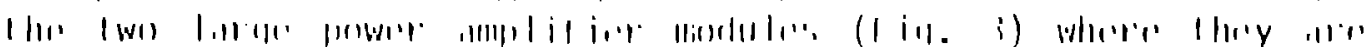

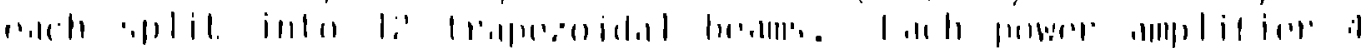

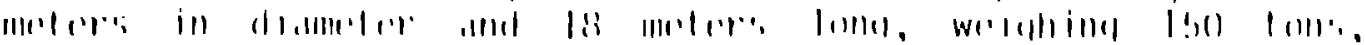

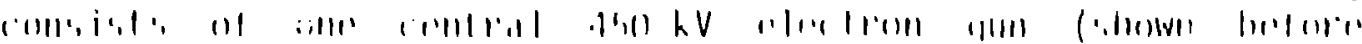

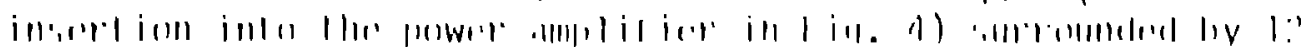




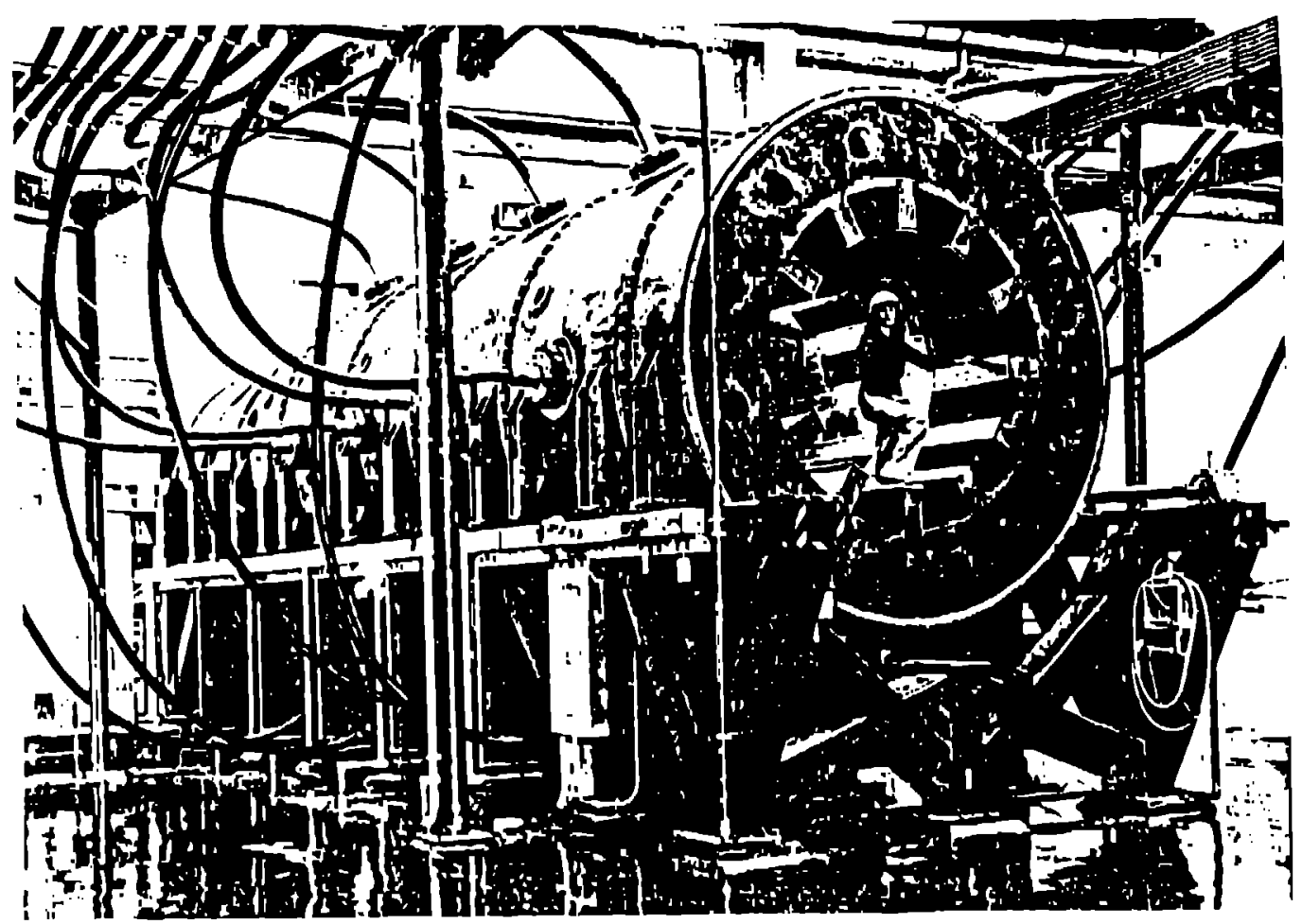

Fi(1. 3

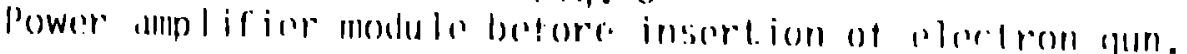

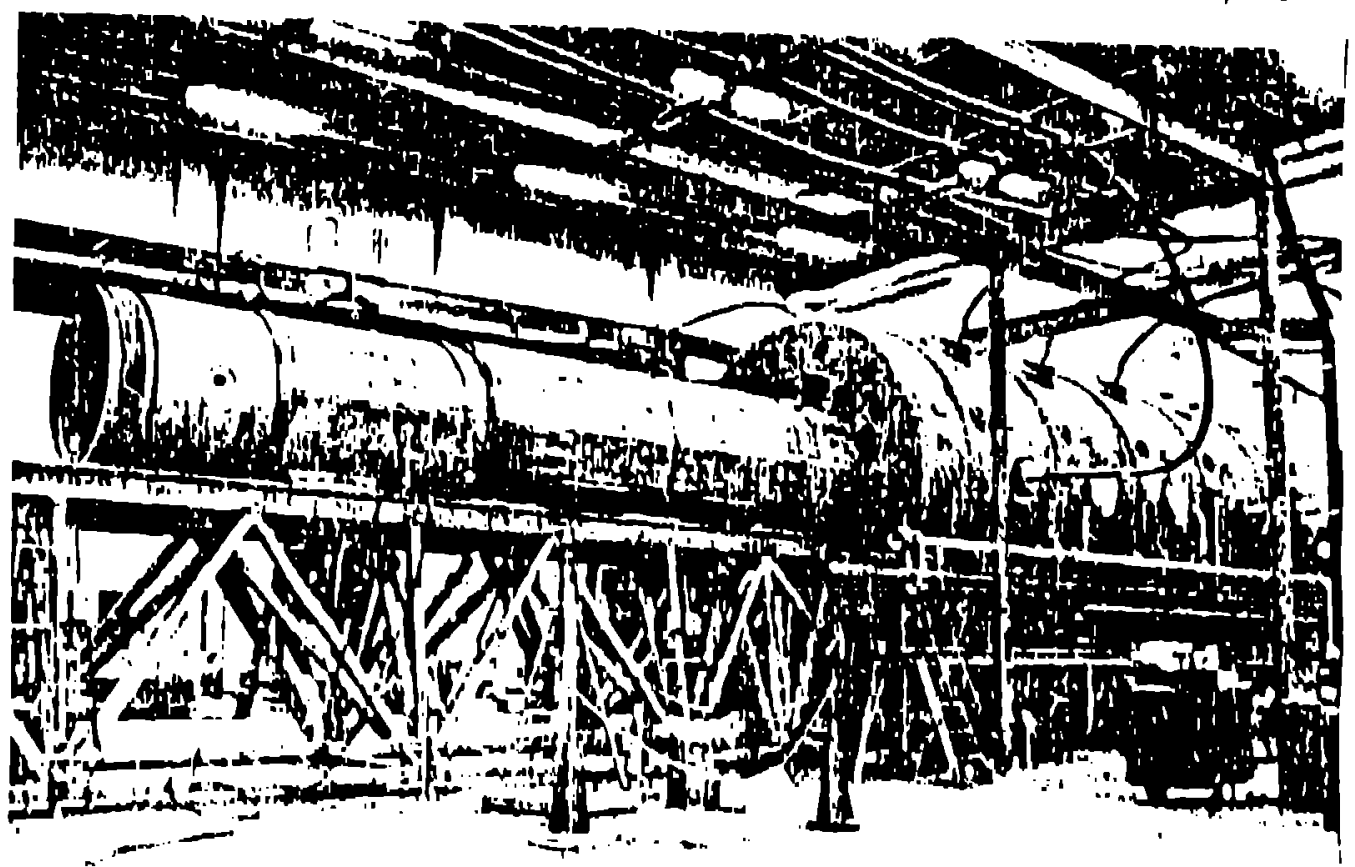

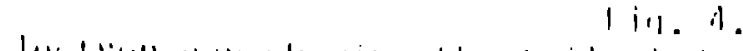

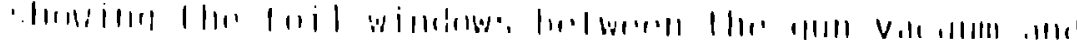
$1 / 1,1,1,1+1,1,1 \cdot$ 
discharge regions. The electron gun is gridded to provide voltage-independent current control and produce the required 50 $\mathrm{mA} / \mathrm{cm}^{2}$ beam density appropriate for optimal preionization of the 1800 torr $\mathrm{CO}_{2}: \mathrm{N}_{2} / 4: 1$ amplifier gas mix. The qun is fed triaxially. To Timit magnetic field effects, the discharge region is divided into four sections along its length providing, in effect, 48 discharge chambers per power amplifier module. Each power amplifier section (four per module) contains one continuous cylindrical anode for all 12 discharge regions and is enerqized by a 10-stage marx qenerator with an open-circuit voltage of $1.2 \mathrm{iV}$, an enerqy storage of $300 \mathrm{KJ}$, and an inductance of $2.5 \mu \mathrm{H}$ to match the gas discharge impedance. A cutaway drawing of a section of a power amplifier module is shown in Fig. 5 .

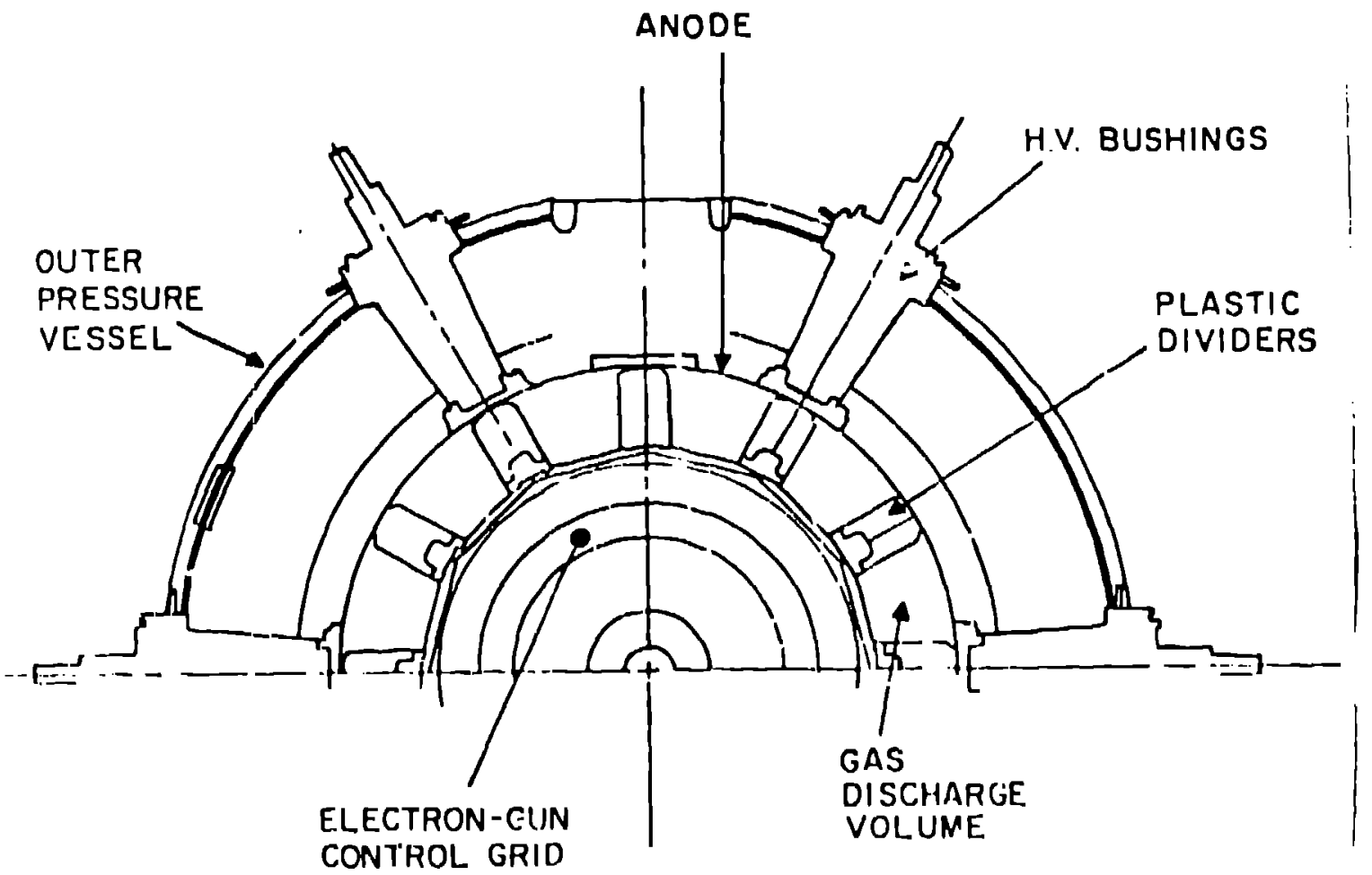

11). !)

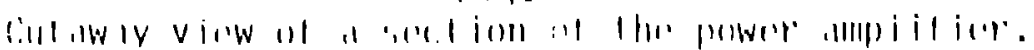

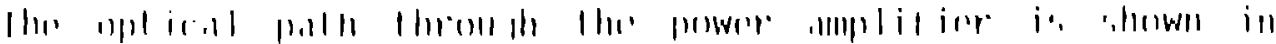

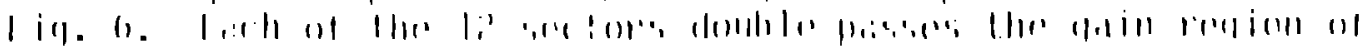

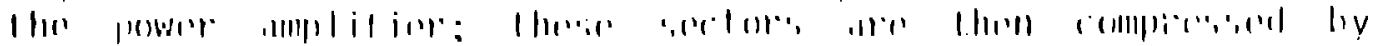

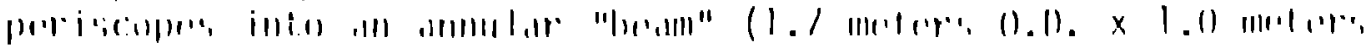

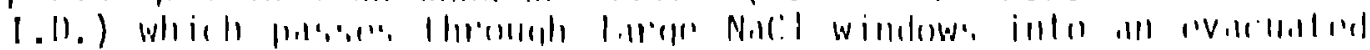

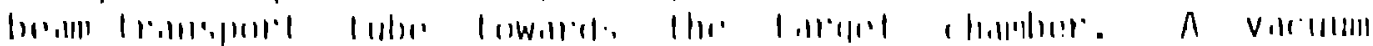

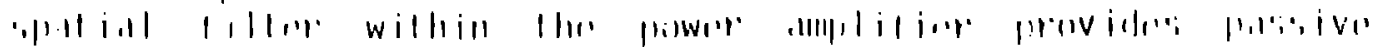

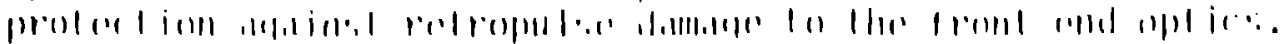



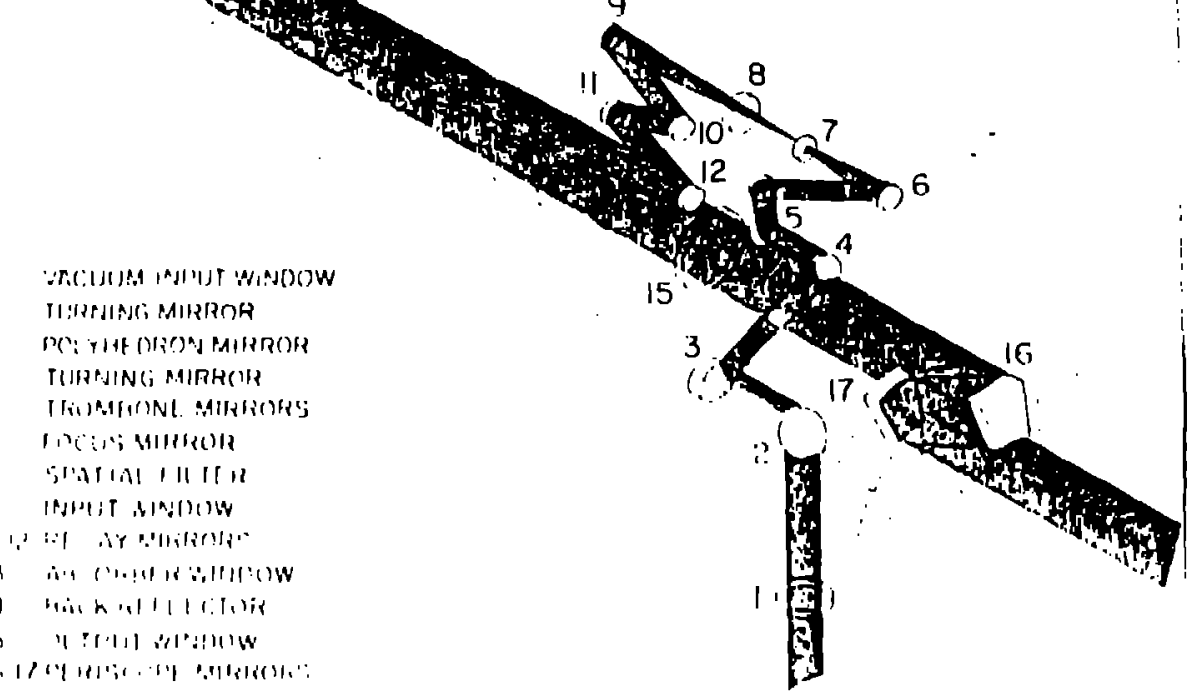

Fin. 6

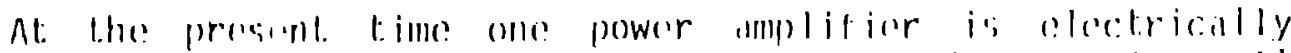

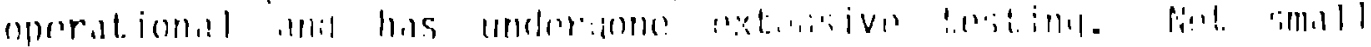

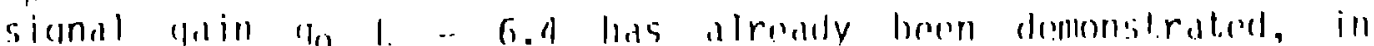

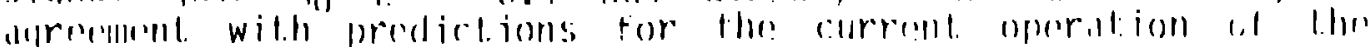

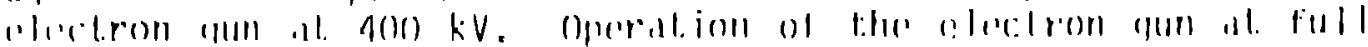

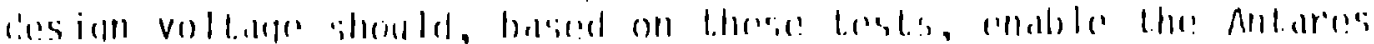

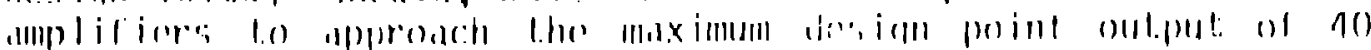

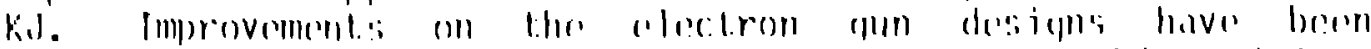

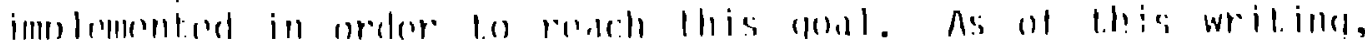

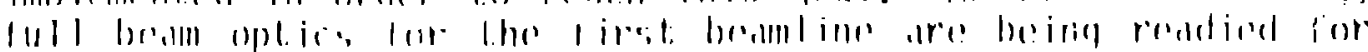

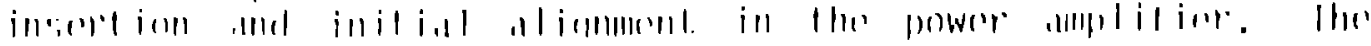

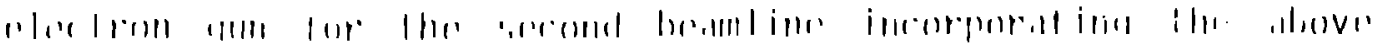

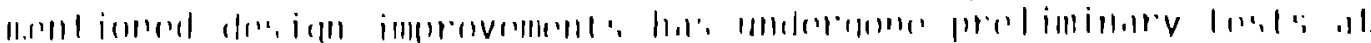
$4 / 1 \mathrm{hV}$.

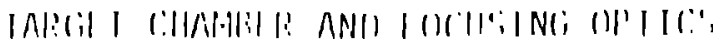

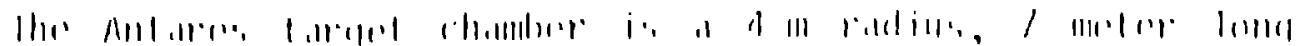

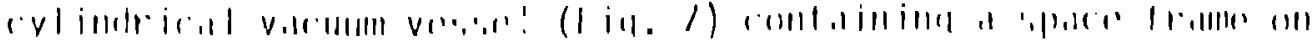




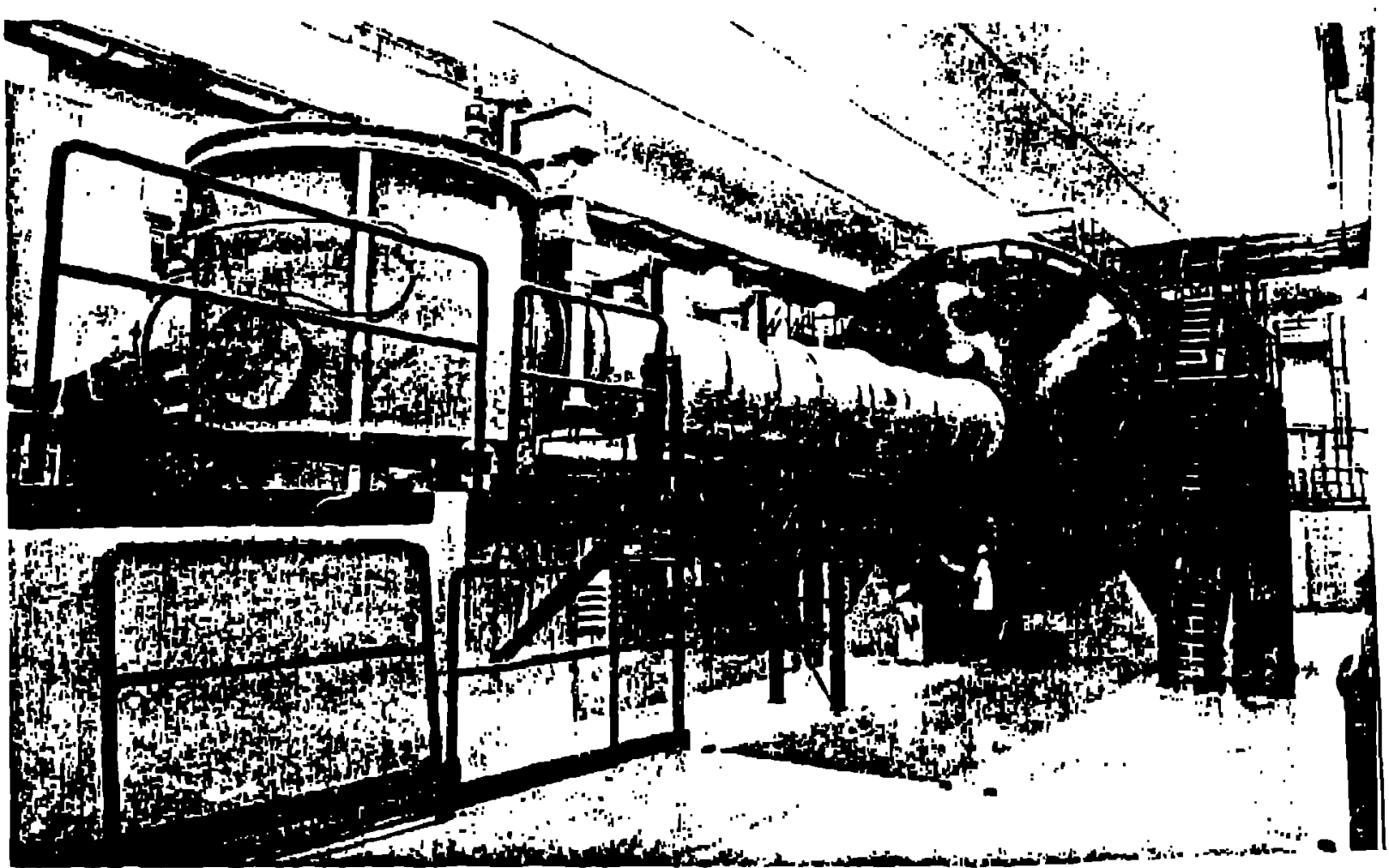

Fia. 7.

The Antares target chamber and evacuated bean tuive.

which are mounted 24 turning mirrors and $24 \mathrm{f} / 6$ focusing paraboloids. Target irradiation is six sided with heams arranged in clusteirs of four, as showr in Fig. B. As are all lurge mirrors in the Antares iysten, the turning and focising mirror; ure simple-point. diamond lurned copper plated on dluminum substrates. The tarnet chamber utilizes cryoconic and turhomolecular pump; lo uchieve a base urossure of ? $x$ lo-fi Lorr with a pump down time of 8 hours. In order to avoill

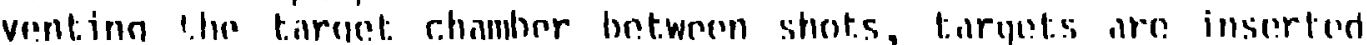

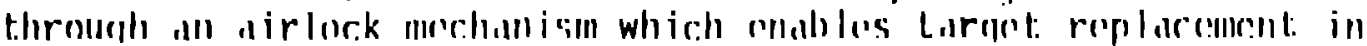

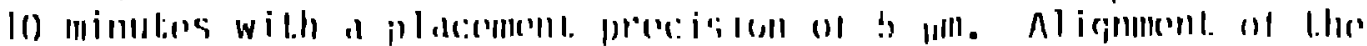

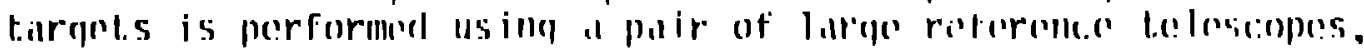

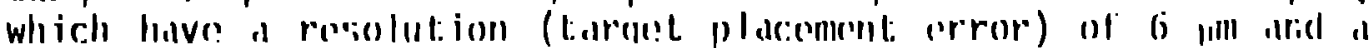
ricld ol virw of I rell diameler. 


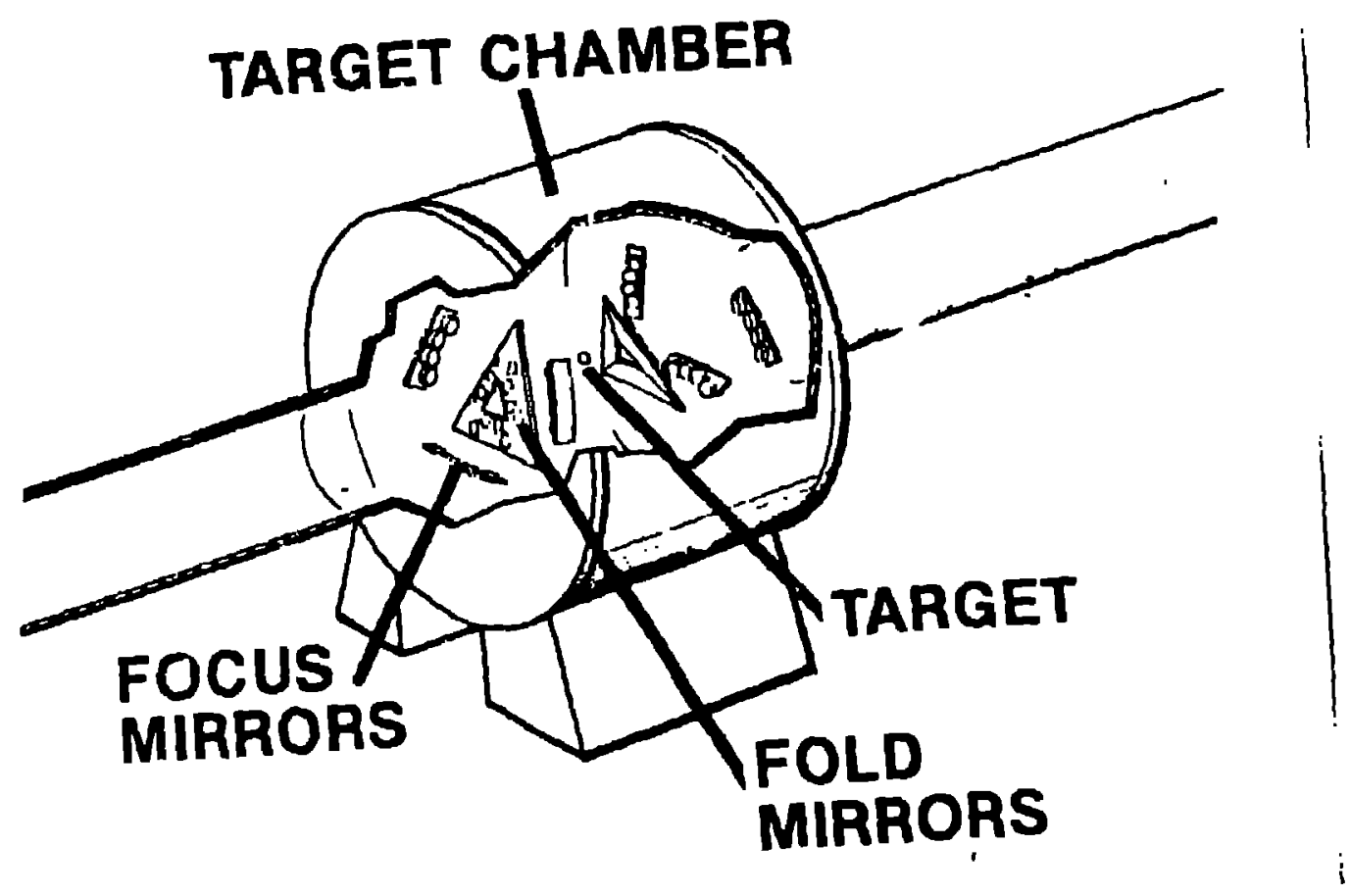

Fig. 8

Final beam pointing and focusina optics.

Tarqet illumination is six-sided.

\begin{abstract}
Alinnment of the laser beams to the tarmet is accomplished by a computer-controllad autumatic alinnment system which can perform a comnlete realignment of all ph beams in ? hours with a pointing pircreision of 75 wall (comporeel to a 300 fum beam spot size). Ream ren.. ming along the optical paths is accomplished by observina light suurces located at the r,enter uf important opticil alements: pointinn to tic tarmet is acleieves by ubserving

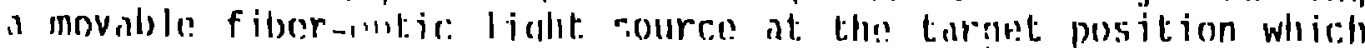

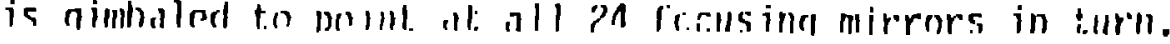

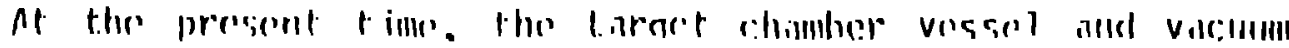

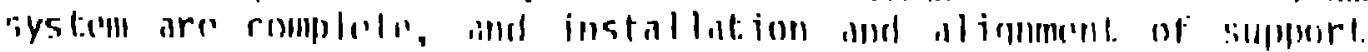

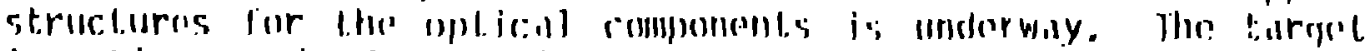

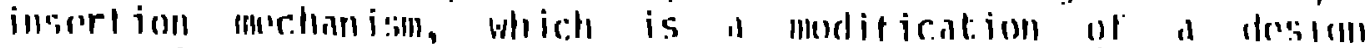

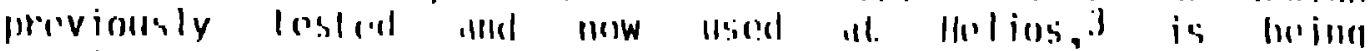

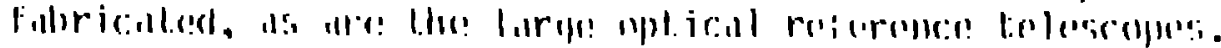




\section{TARGET DIAGNOSTICS}

Experiments on antares wiil assess the efficiency with which $10 \mu \mathrm{m}$ light can be utilized to drive hydrodynamic implosions with appropriate levels of preheat, as an extension of current Helios experiments. The initial operation of the facility in early FY-84 will be aimed at verifying the energy scali $\exists$ of important features of the laser-target interaction: absorption and energy balance (including fast ion generation), hot electron deposition, and target heating.

In order to achieve these goals we are fielding the following initial set of diagnostics: (1) A pair of $x$-ray pinhole cameras for verification of beam alignment on target. These cameras are inserted into the chamber through an air-lock mechanism to enable retrieval of $f i l m$ and changes of pinholes and filters between each shot. Pinhole imaging is also used to determine the spa'ial distribution of hot electron deposition in the taraet. The pinhole cameras will view the target from the ends of the chamber near the beam transport tubes.

(2) An array of 26 plasma calorimeters to determine the absorbed eneray by measuring the energy in the ion expansion (time-inteqrated). Several cjlorimeters will be filtered, e.q. with $0.5 \mathrm{\mu m} \mathrm{Ni}$, to determine the eneray invested in the fast ion expansion ( $0.5 \mu \mathrm{m} \mathrm{Ni}$ stops 10$) \mathrm{keV}$ protoris). These caiorimeters will be distributed in an arrangement which provides roughly uniform sampling of the ion anaular cistribution.

(3) A 10-chanrel filter/scintillator/photodinde hard x-ray spectrometer known by the acronym APACIIE. ${ }^{4}$ Filters and scintillator: provide broadband channel response in the ranqe 30-500 keV. A fit to the sianals from individual channels (assuming a Maxwellian orensstrahlung spectrum) determines the: hot electron temperature and the amount of hot electron ellergy colitsionally depnsited in the tirqet. The detector system provicles 10 ns resolution and is therefore time-inteirated on the time scale of the laser interaction, although time resolved compared to electrical noise backsround.

(A) A 7-r.hannel filtered x-ray diode array (MII.TIFLEX)s with a 250 ps systam rigntime. The photonelectric responses of the aluminum photocathodes arre filler trunsinission characteristics mable enverane of the spect:rum betiveren - $30 \mathrm{ov}$, and -

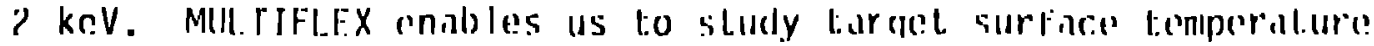
and deteraine the heating dur to hot oleretron deposition.

(5) A sott x-ray collimetor comprised of an array of 7

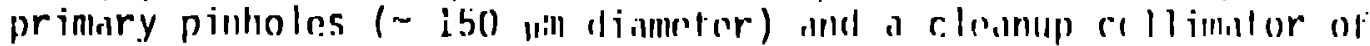

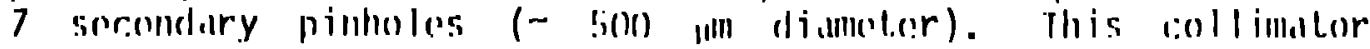


(assuming a Maxwellian bremsstrahlung spectrum) determines the hot electron temperature and the amount of hot electron energy collisionally deposited in the tarnet. The jetector system provides 10 ns resolution and is therefore time-integrated vi: the time scale of the laser interaction, aithough time-resolved compared to electrical noise background.

(4) A 7-channel filtered x-ray diode array (MULTIFLEX) ${ }^{5}$ with 250 ps system risetime. The photoelectric responses of the aluminum photocathodes and filter transmission characteristics enable coverage of the spectrum between $\sim 30 \mathrm{eV}$ and $2 \mathrm{keV}$. MULTIFLEX enables us to study target surface temperature and determine the heating due to hot electron deposition.

(5) A soft $x$-ray collimator comprised of an array of 7 primary pinholes ( 150 , Im diameter) and a cleanup collimator of 7 secondary pinholes (- $500 \mu \mathrm{m}$ diameter). This collimator serves to limit the field of view of the MULTIFLEX diodes to a common $400 \mathrm{um}$ diameter spot in the target plane, enabling a determination of the brightness temperature of the target surface unaffected liy coniiderations of source size. The collimator pinholes are locatird 10 and $20 \mathrm{~cm}$ from the tarqet and are optically aligned with the MilJLIFLEX diodes to a positioning accuracy of $25 \mu \mathrm{m}$. Both MULTIFLEX and APACHE view the tarqet fiom the "equator" of the target chamber.

All of these diagnostics are modifications of tested instrumentation currently in use at Helios, but represent oniy' a fraction of the tested diannostics used at that facility, which include d variety uf specliroaraphs, Faraday cups and Thoinson parabolas, and optical diacnostic:i. Many of those diagncistics will be anded durina the operational phase of Antares. Des"qns for the pinhole cameras are complete, and fabrication of the plasma calnrimeters is well under vil,. Modifications of MULTIFLEX and APACIIE are undernoi, engineering design. The instrumentation is scheduled for installaticn and checkout prior 1.0 Antares turnon in early $F y-34$.

\section{C.ONCLLISIONS}

Antaros is a larne, 30-10 kal con laser system which will provide a base for experimenl.s to determint the efficicency with which lo pull lioht can be used to drive taront implosions while?

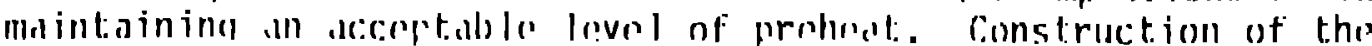
Facility is in the tillal siagos and diannostics for initial reperiments are boind elessimned and constructend wilih operations

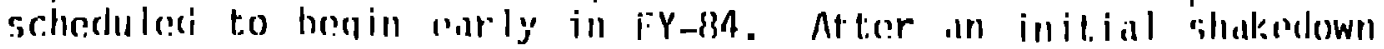
period, we experct lo perturm a series of mensurementes to determine the eneruy is.alime of hot: electiron bomperature and

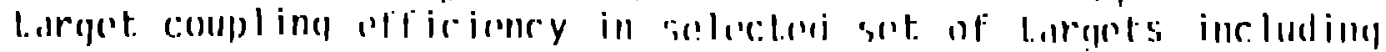


simple spheres. We also expect to continue experiments, now planned for Helios, to determine whether $\mathrm{CO}_{2}$-produced ions are appropriate for driving inertial fusion targets with acceptable efficiency (Helios experiments have demonstrated that as much is 40. of the incident light can be converted to fast ions). Details of these experimencs, as well as plans for further experiments, are still being defined.

\section{REFERENCES}

1. R. L. Carlson, et al., IFEE J. Quantum F.lectron. 17, $1 \epsilon 62$ (1981).

2. S. Sinner, "Laser Interaction and Related Plasma Phenomena," V. 4A, p. 181, 4. Schwarz and I!. Hora, eds., Plenum, Now York, New York, (1977).

3. R. Day, C. Cumming̣s, J. Hanlon, II. Tucker, and R. Teasdale, SPIE, V. 190, 19i (1979).

4. W. Priedhorsky, II. I.ier, R. llay, and I). (iterke, Phys. Rev. l.et.t. 17, $16(61$ ilysil).

b. R. H. May, R. Hesckadlity, F. Amederi, !. Bemmelli, and W.

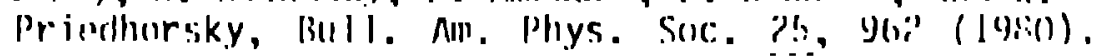

